\title{
THE ROLE OF ADIPOKINES IN BONE HOMEOSTASIS
}

\section{Ippei Kanazawa}

Department of Internal Medicine 1, Shimane University Faculty of Medicine, Izumo, Japan

\begin{abstract}
Growing evidence has shown that adipose tissue accumulation is associated with bone metabolism. Arguably, adipokines, secretory proteins of adipose tissue, are involved in bone homeostasis including development and remodeling. The "classical" adipokine leptin regulates bone formation negatively and bone resorption positively via central nervous system. Leptin also stimulates directly osteoblastogenesis and inhibits osteoclastogenesis through stimulation of osteoprotegerin and inhibition of receptor activator for nuclear factor $\mathrm{k} B$ ligand (RANKL) expression in osteoblasts. Another major adipokine, adiponectin, and its receptor are expressed in osteoblasts. Adiponectin stimulates the proliferation, differentiation, and mineralization of osteoblastic cells, and indirectly stimulates osteoclast differentiation via enhancement of RANKL and inhibition of osteoprotegerin expression in osteoblasts, whereas directly inhibits osteoclast activity and bone resorption. Altogether, adipose tissue via adipokines plays a crucial role in the maintenance of bone homeostasis. These findings are reviewed herein.
\end{abstract}

Adipobiology 2011; 3: 39-50

Key words: leptin, adiponectin, osteoblast, osteoclast, bone metabolism

Received 15 December 2011, revised 26 December 2011, accepted 27 December 2011.

Correspondence: Ippei Kanazawa, MD, PhD, Department of Internal Medicine 1, Shimane University Faculty of Medicine, 89-1

Enya-cho, Izumo 693-8501, Japan. Tel.: +81-853-20-2183; Fax: +81-853-23-8650 ; E-mail: ippei.k@med.shimane-u.ac.jp

\section{Introduction}

Osteoporosis has become a major medical problem in the last half century, largely as the result of increased longevity and a changing lifestyle (1). Osteoporosis has been defined as a skeletal disease characterized by low bone mass and microarchitectural deterioration of bone tissue with a consequent increase in bone fragility and susceptibility to fracture. The number of patients with osteoporosis is rapidly increasing especially in industrialized countries. It is very important to prevent osteoporotic fractures because they frequently occur and enhance the mortality of the elderly people as high as 6- to 9-fold (2,3). It is reported that $7 \%$ of survivors of all types of fracture have some degree of permanent disability and $8 \%$ require long-term nursing care (4). Overall, a 50-year-old woman has $13 \%$ chance of experiencing functional decline after any fracture. In addition to its effect on health, osteoporotic fracture has a huge impact economically.

In healthy adults, bone mass and turnover are maintained by coordinated balance of two major types of cells: osteoblasts and osteoclasts. Osteoclasts move to resorb mature bone tissue and micro-damage constantly 
(bone resorption), and then osteoblasts form new bone tissue in the lacunar pit (bone formation), controlling the reshaping and replacement of bone. A number of systemic and local factors are involved in the regulation, such as insulin, insulin-like growth factor-I (IGF-I), and bone morphogenetic proteins (BMPs) $(5,6)$. However, the mechanism of bone remodeling is not fully understood to date.

Recent studies have revealed that adipose tissue is not only an energy-storing, but also a secretory tissue producing a variety of biologically active proteins named adipokines (7). Growing evidence shows that there is a positive correlation between bone mineral density (BMD) and fat mass, and that fat accumulation affects bone metabolism $(8,9)$. Although mechanical loading may contribute to this relationship, other factors are also involved. Leptin and adiponectin have recently attracted widespread attention, especially in the diabetes field, due to its beneficial antidiabetic effect in the regulation of energy homeostasis and insulin sensitivity (10). Several studies suggest that leptin and adiponectin in the circulation are involved in bone metabolism (11-13). Leptin, a $16 \mathrm{kD}$ protein mainly secreted by white adipose tissue and strongly correlated positively with body fat mass, regulates various biological functions including appetite and reproduction $(14,15)$. Leptin is reported to regulate bone mass accumulation via a hypothalamic relay. On the other hand, it is reported that mesenchymal progenitor cells and osteoblasts have functional leptin receptors, suggesting that leptin also directly regulates osteoblastogenesis and osteoblast differentiation.

Another major adipokine, adiponectin, is specifically and highly expressed in visceral and subcutaneous fat as well as in bone marrow fat depots and is abundantly present in plasma (16). It is a $30 \mathrm{kD}$ polypeptide containing an $\mathrm{N}$-terminal signal sequence, a variable domain, a collagen-like domain, and a C-terminal globular domain (17). Adiponectin receptor (AdipoR) has been identified, and the biological effects of adiponectin are mediated through the two adiponectin receptor subtypes, AdipoR1 and AdipoR2 (18), which belong to the seven-transmembrane-spanning receptor; the $\mathrm{N}$-terminus is internal and the $\mathrm{C}$-terminus is external; an opposite topology to the other reported $G$ protein-coupled receptors (19). Several studies have shown that adiponectin and its receptor are expressed in osteoblasts (20-22), suggesting that bone metabolism is affected by adiponectin. Furthermore, a few studies reported that other adipocytokines such as resistin and visfatin may be involved in bone metabolism. In addition, bone has recently emerged as an endocrine organ affecting adipose tissue accumulation and glucose homeostasis through osteocalcin $(9,23,24)$. In this review, I summarize the effects of adipokines, such as leptin, adiponectin, resistin, and visfatin, on bone cells and bone mass in vitro and in vivo.

\section{Leptin maintains bone homeostasis through the central nervous system}

Leptin is a major hormonal product of the adipose tissue that regulates appetite and reproductive function. Leptin acts as a satiety signal, working through the hypothalamus to stimulate feeding when leptin levels in circulation are decreased with low fat mass and to inhibit food intake when energy stores are plentiful (25). Mouse obese (ob) gene encodes leptin (26). The gene is disrupted in the naturally occurring leptin-deficient mutant, $o b / o b$ mice. The $o b / o b$ mice are hyperphagic and suffer from obesity and type 2 diabetes because of lacking the satiety and insulin-sensitizing signal from leptin (27). Leptin receptors, a single-transmembrane-domain receptor of the cytokine receptor family (28), are widely distributed in peripheral tissues, including skeletal muscle, bone, and cartilage, but a primary target of leptin is the brain, specifically the hypothalamus. Another mouse model lacking leptin signaling, $d b / d b$ mice, has a mutated and inactive leptin receptor. As with the leptin-deficient $o b / o b$ mouse, the phenotype of the $d b / d b$ mouse is characterized by hyperphagia, obesity, hyperglycemia, and hyperinsulinemia (29). On the other hand, the bone phenotypes of the $o b / o b$ and $d b / d b$ mice are puzzling because there is some variability in the magnitude and direction among previous published research. Some investigators reported the mice lacking leptin receptor have low bone mass (30-33), whereas others showed high bone mass in the mice (34). The reasons for these discrepancies remain unclear.

Ducy et al (34) previously reported that the $o b / o b$ and $d b / d b$ mice had higher trabecular bone mass associated with a higher mineral apposition rate (MAR) when compared with their wildtype littermates, suggesting that leptin exerts a negative effect on bone formation and bone mass accumulation. These authors further explored the alteration of bone in the mice by showing that leptin acts on the skeleton through an indirect pathway via its hypothalamic relay. In fact, intracerebroventicular (ICV) infusion of leptin (192 ng/day) for 28 days to the $o b / o b$ mice normalized their bone phenotypes. In addition, ICV leptin infusion in wild-type mice led to rapid bone loss in the vertebrae. It was demonstrated that an orexigenic protein, neuropeptide tyrosine (NPY), which is secreted by the hypothalamus and downregulated by leptin in the satiety control loop, decreased bone mass when administrated intracerebroventicularly, and that deletion of its hypothalamus-specific receptors had opposite effects with increased bone mass $(34,35)$. Furthermore, Takeda et al demonstrated that leptin central antiosteogenic function was mediated by the sympathetic nervous system (36). Leptin binds to receptors on the hypothalamus, inducing an increase in sympathetic activity which signals to osteoblasts via the b2 adren- 
ergic receptors presented at their surface. They also showed an evidence that b-adrenergic antagonist induced an increase in bone mass in the mice. It is suggested that the sympathetic signal stimulated by leptin inhibits osteoblast proliferation via the molecular clock regulation of $c-m y c$ and Cycline-D expression and promotes Rankl expression, while leptin increases the expression of Cart, a gene encoding cocaine amphetamine regulated transcript (CART), in the hypothalamus, which increases Rankl expression (37). Taken together, these findings suggest that leptin has a negative impact on bone mass by inhibiting osteoblast proliferation and increasing osteoclast activity through the central nervous system and using two neural mediators, the sympathetic nervous system and CART. In contrast, Iwaniec et al (38) reported different central effects of leptin on bone mass as compared with that reported by Ducy et al (34). Iwaniec et al (38) demonstrated that $o b / o b$ mice treated with a recombinant adeno-associated virus expressing leptin in the hypothalamus displayed increases in femoral bone mass and length as well as a decrease in cancellous bone volume. Moreover, blood osteocalcin levels were increased in wild-type and $o b / o b$ mice injected with the recombinant leptin-expressed adeno-associated virus, whereas basal osteocalcin levels in $o b / o b$ mice were significantly lower as compared to those in wild-type mice (39). Bartell et al (40) showed that ICV injection of $0.38 \mathrm{mg} /$ day and $1.5 \mathrm{mg} /$ day leptin for 12 days induced the expression of Runx2, osterix, and alkaline phosphatase (ALP) in femoral bone marrow and inhibited the expression of receptor activator for nuclear factor k B (RANK) and macrophage colony-stimulating factor. Moreover, whole-body BMD and body mineral content (BMC) as well as MAR were increased in the mice administrated intracerebroventicularly. The apparent difference between Bartell et al's and Ducy et al's data may be due in part to the differences in doses administrated ICV (1.5 mg/day versus $192 \mathrm{ng} /$ day $)$ and the duration of treatment (12 days versus 28 days). In addition to Bartell et al's findings, overexpression of leptin in hypothalamus increased femoral length and volume (38). Therefore, high dose administration of leptin ICV might have an anabolic effect on bone. However, it is suggested that leptin resistance may exist when having high concentration of leptin. Indeed, the leptin levels in the circulation are positively correlated with body weight and fat mass, and obese patients have high blood leptin levels despite leptin has beneficial effects on the hyperphagia and gain of body weight. It is reported that leptin itself induces the leptin resistance in the hypothalamus (41). Therefore, the high dose administration and overexpression of leptin might induce the resistance to negative effects of leptin on bone mass. The central regulation of bone mass is complex and incompletely understood. Previous studies showed that many neurotransmitters and neuropeptides such as neuromedin U, NPY, serotonin, and cannabinoid receptors are involved in bone metabolism $(42,43)$. Further studies are thus necessary to understand the regulation of leptin in bone metabolism through the central nervous system.

\section{Direct regulation of bone metabolism by leptin}

Previous studies have shown that mesenchymal stem cells and osteoblasts are targets for leptin action, as these cells express functional leptin receptors $(44,45)$. Both two types of leptin receptors, short-form and long-form, are shown to be expressed on the surface of bone marrow stromal cells (BMSC) and osteoblasts (46). In response to leptin stimulation, rapid induction of phosphorylation of Stat3, a downstream of leptin signaling, was observed in the BMSC.

The effects of leptin on proliferation of mesenchymal stem cells and osteoblastic cells were investigated by several groups. Takahashi et al (46) demonstrated that leptin stimulated the proliferation of C3H10T1/2, a mouse embryonic cell line, in a dose- and time-dependent manner. It was found that mitogenactivated protein kinase (MAPK)-specific inhibitor PD98059 completely blocked the increases in both MAPK activity and cell proliferation caused by leptin, suggesting that the stimulatory effect of leptin on cell growth of C3H10T1/2 is depend on MAPK pathway. Leptin caused a significant increase in the activation of PI3-kinase that was accompanied by an increase in cell proliferation dose dependently (47). Leptin activated MAPK and PD98059 blocked DNA synthesis induced by leptin (46), whereas this adipokine increased the proliferation of isolated fetal rat osteoblasts comparably with IGF-I, a major anabolic factor of bone formation (48). Moreover, several in vitro studies examined the effects of leptin on the commitment of mesenchymal stem cells to osteoblast lineage and the differentiation of osteoblasts. Leptin increased mRNA and protein levels of ALP, type I collagen, and osteocalcin in dose- and time-dependent manner as well as enhanced mineralized matrix in human marrow stromal hMS2-12 cells (49). Leptin had the ability to up-regulate type I collagen gene expression in osteoblastic MG63 cells (50). Similar results are reported in other cell models as showing increased cell growth of osteoblastic lineage and mineralization by leptin (51-53). Furthermore, in vitro deletion of leptin receptor exhibited significant less mineral apposition compared with control bone marrow stromal cells (45). In addition, it is reported that leptin protected retinoic acid-induced apoptosis in primary human osteoblast cultures, leading to enhancement of osteoblastic activity (53).

Although Takeda et al (36) reported that transgenic mice expressing leptin in osteoblasts had no overt bone abnormalities, 
several interventional studies examining the effects of peripheral leptin administration showed that leptin directly affects bone mass in different animal models. Leptin administration led to a significant increase in femoral length, total body bone area, $\mathrm{BMC}$, and $\mathrm{BMD}$ in $o b / o b$ mice as compared to vehicle treated controls (31). Further, such a treatment increased both trabecular and cortical bone mass and reversed the defect in bone growth and osteopenia, as measured by dual energy X-ray absorptiometry (DXA) and peripheral quantitative computerized tomography (qCT). Moreover, systemic daily administration of leptin to adult male mice reduced bone fragility by more than $20 \%$ (48). Using tail-suspended female rats, a model of rapid bone loss characterized by an uncoupling pattern of bone remodeling, intraperitoneal leptin administration prevented tailsuspension induced a progressive decrease in tibia-metaphysis
BMD by DXA and a decrease in bone formation rate by histomorphometry (54). Administration of leptin to ovariectomized rats prevented the rapid bone loss induced by estrogen deficiency (55). Of note, the combination of estrogen and leptin further decreased bone turnover compared with that in estrogen-treated ovariectomized rats. In addition, leptin increased osteoprotegerin (OPG) mRNA expression and protein production as well as decreased RANK ligand (RANKL) mRNA levels, leading to inhibition of osteoclastogenesis. In contrast, ovariectomized rats injected with a recombinant adeno-associated virus expressing leptin in the hypothalamus showed no change in bone volume by micro-CT and histomorphometry compared with ovariectomized rats (56). Taken together, these studies by peripheral administration of leptin suggest that leptin is able to directly and positively affect bone mass and remodeling.

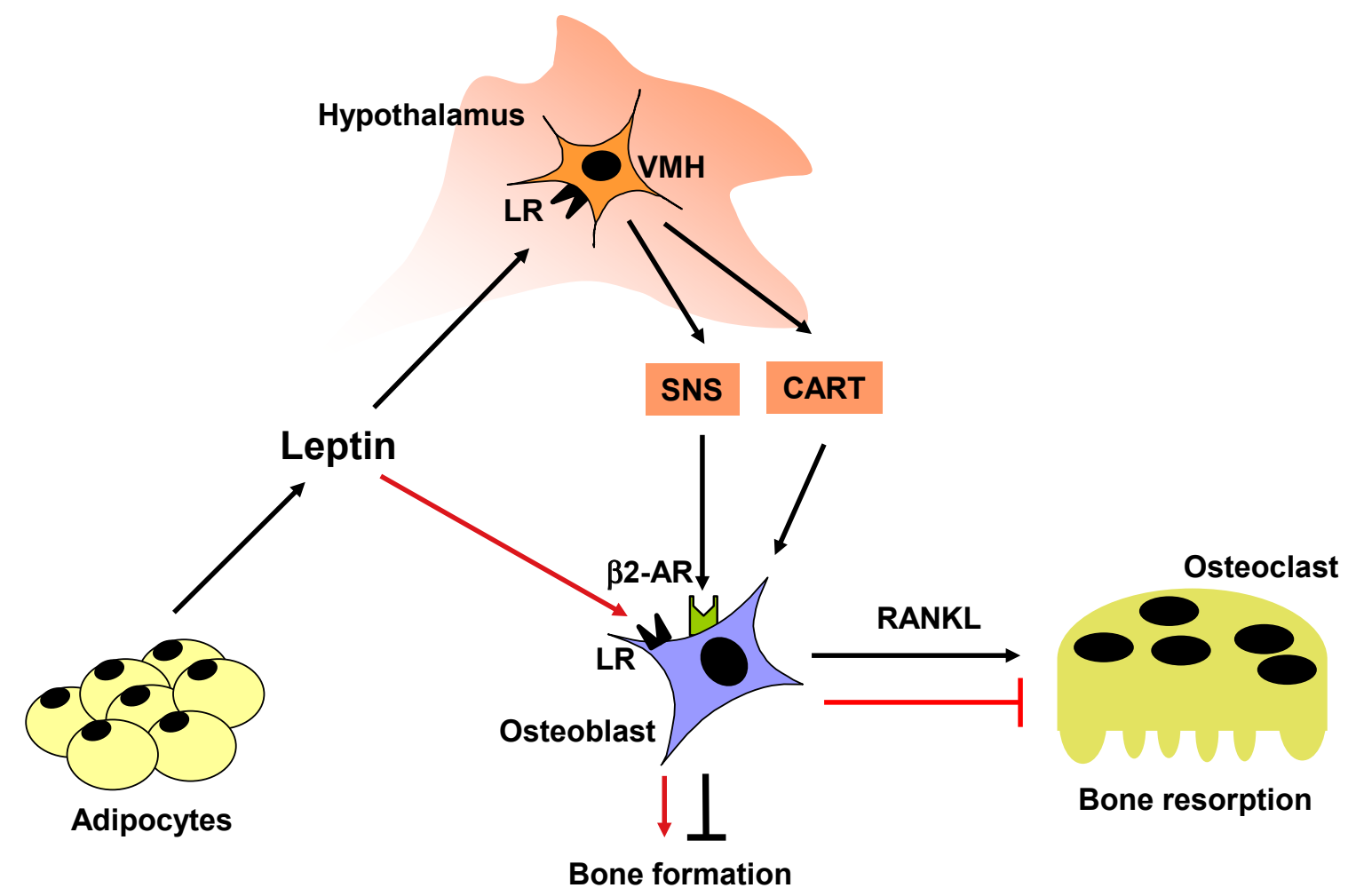

Figure 1. Schematic representation of the direct and indirect effects of leptin on bone metabolism. Leptin secreted from adipocytes binds to its receptor expressed in the hypothalamus and stimulates sympathetic nervous system, leading to inhibition of bone formation via $\beta 2$ adrenergic receptors as well as activation of bone resorption via RANKL expression in osteoblasts. Leptin also increases CART expression in the hypothalamus, which promotes RANKL expression. On the other hand, leptin directly stimulates osteoblastogenesis and bone formation via leptin receptor and inhibits osteoclast differentiation via inhibition of RANKL expression.

LR, leptin receptor; $V M H$, ventromedial hypothalamic nucleus; SNS, sympathetic nervous system; CART, cocaine amphetamine regulated transcript; $\beta 2 A R, \beta 2$ adrenergic receptor; RANKL, receptor activator for nuclear factor $\mathrm{K} B$ ligand. Red arrow indicates direct effect of leptin. Black arrow indicates indirect effect of leptin. 


\section{Adiponectin regulation of bone mass}

It has been shown that adiponectin is expressed in osteoblastic cells. Adiponectin mRNA expression and its protein secretion are detectable in vitro in osteoblasts and in vivo in mandibular bone of rat (57). Furthermore, adiponectin is also found in bone marrow-associated adipocytes (58), and the adiponectin level is higher in diluted bone marrow fluid than in the serum of rats (59). These facts suggest that adipocytes as well as bone cells contribute to the production and high concentration of adiponectin found in bone marrow. On the other hand, although the mRNA of AdipoR1 and AdipoR2 is expressed in primary human osteoblasts (57,59), AdipoR1, but not AdipoR2, protein is detectable by Western blot assay (59). We also confirmed that MC3T3-E1 cells expressed only AdipoR1 (20). These findings suggest that adiponectin carries signals and plays a role in bone tissue through the autocrine, paracrine, and endocrine pathways.

The stimulatory effect of adiponectin on osteoblast proliferation has been reported by several research groups (56,58-60). Luo et al (58) demonstrated that adiponectin promotes osteoblast proliferation and that suppression of AdipoR1 by smallinterfering (siRNA) abolished adiponectin-induced cell proliferation. In addition, adiponectin activated c-jun $\mathrm{N}$-terminal Kinase (JNK), and the stimulatory effect of adiponectin on cell growth was blocked by the siRNA of AdipoR1 and a JNK inhibitor. We also confirmed that adiponectin treatment significantly stimulates the proliferation of MC3T3-E1 cells (59). The central modulator of the signaling cascade triggered by the adiponectin receptor is adenosine monophosphate-activated protein kinase (AMPK), which plays a key role in energy homeostasis and all metabolic effects exerted by the hormone and energy homeostasis (61). In our experiments, adiponectin stimulated AMPK phosphorylation in osteoblasts and AMPK activation by aminoimidazole-4-carboxamide ribotide, a pharmacological activator of AMPK known as AICAR, induced cell proliferation $(59,62)$. Therefore, adiponectin stimulates cell growth of osteoblasts via activation of the JNK and AMPK pathways. Furthermore, several in vitro studies have shown that adiponectin has a stimulatory action on the differentiation of osteoblasts and induces osteoblastic differentiation of mesenchymal progenitor cells. It was previously demonstrated that adiponectin treatment increased ALP activity, osteocalcin and type 1 collagen production, and mineralized matrix in dose- and time-dependent manners (58). We also demonstrated that reduction of AdipoR1 expression by siRNA of AdipoR1 decreased mRNA expression of type 1 collagen and osteocalcin, ALP activity, and the mineralization defined by von Kossa and Alizarin red stainings in MC3T3-E1 cells
(59). Adiponectin increased mRNA and protein levels of BMP-2 in cultured osteoblastic cell lines, MG-63 and hFOB (63), and the adiponectin-induced BMP-2 expression was attenuated by the siRNA of AMPK and AMPK inhibitors. Adiponectin stimulated BMP-2 and Runx2 expression and induced the commitment of mesenchymal stem cells into an osteoblast lineage as well as the differentiation of osteoblasts (64). Furthermore, we found that adiponectin stimulated the expression of osterix (59), an essential osteogenic transcription factor downstream of the BMP-2 signaling pathway; osterix promoter activity is also increased by adiponectin treatment (65). These findings confirm that BMP-2 signaling molecules are involved in the stimulatory effect of adiponectin on osteoblasts.

It is reported that adiponectin receptor is expressed in not only osteoblasts but also osteoclastic cells (66) and that adiponectin directly inhibits osteoclastogenesis and bone resorption. Treatment of osteoclastic cells with adiponectin after MCSF/RANKL-induced differentiation resulted in a significant reduction of the resorption area in a dose-dependent manner (67). Adiponectin has an inhibitory effect on osteoclast formation using a mouse macrophage-like cell line, RAW264 (68). In addition, suppression of AMPK activity abrogated the inhibition of nuclear factor of activated T cells 2 (NFAT2) (also known NFATc1) expression by adiponectin treatment (69). Adiponectin treatment dramatically inhibits the induction of the osteoclastogenic regulators such as NFAT-2, cathepsin K, and tartrate-resistant acid phosphatase (TRAP) by RANKL and the mRNA level of tumor necrosis factor (TNF) receptor-associated factor 6 (TRAF6) (65). Adiponectin was also found to increase osteoclast apoptosis and decrease proliferation of osteoclast precursor cells. It was demonstrated that osteoclastogenesis was significantly inhibited by adiponectin in primary mouse bone marrow cultures, while no effects of adiponectin were observed on RAW-264 cells treated with RANKL or on isolated mature osteoclasts, suggesting that adiponectin inhibits osteoclast formation but has no effect on mature osteoclast activity (70). In contrast, Shinoda et al (66) reported that the number of cultured osteoclasts isolated from adiponectin knockout mice showed no difference compared with wild-type cells. On the other hand, adiponectin regulated bone turnover via enhancing RANKL expression and suppressing OPG in osteoblasts although adiponectin treatment had no direct effect on these cells (71). Adiponectin treatment induced RANKL and inhibited OPG mRNA expression in a dose- and time-dependent manner. Suppression of AdipoR1 with siRNA abolished the adiponectin-regulated RANKL and OPG mRNA expression, and pretreatment of osteoblasts with a p38 MAPK inhibitor abolished adiponectinregulated RANKL and OPG mRNA expression. They also found 
that adiponectin induced osteoclast formation in the co-culture systems of osteoblasts and human osteoclast-like cells and that OPG entirely blocked this response. Overall, although a few studies reported no effect of adiponectin on osteoclasts, most other in vitro studies showed that adiponectin inhibits osteoclast activity and bone resorption, while adiponectin accelerates bone turnover via enhancement of RANKL and inhibition of OPG in osteoblasts.

However, several in vivo studies using overexpression and knockout models of adiponectin show conflicting results. Overexpression of adiponectin in the liver enhanced bone formation and showed a gain of bone mass compared with wild-type mice $(67,72)$, whereas adiponectin-overexpressing mice had a significantly lower bone mass and that the peak load of femur neck and vertebra was significantly lower than wild-type mice (73). There is not significant differences in bone mass or turnover in adiponectin-overexpressing mice in the liver or in adiponectin knockout mice compared with their littermates (66). It is wellknown that adiponectin enhances insulin activity and reduces insulin resistance. Most studies have consistently shown that adiponectin knockout mice have either spontaneous or dietinduced insulin resistance with hyperinsulinemia (74), which affects bone metabolism and causes an increase in bone mass. Adiponectin also plays important roles in the liver, muscle, pancreas, and hypothalamus, which might affect bone metabolism. In addition, because adiponectin receptors are ubiquitously expressed in various tissues, adiponectin may have both direct and indirect effects on bone. Therefore, regarding the conflict results of these in vivo studies, physiological compensation and adaptation might contribute to the complexity of the in vivo role of adiponectin in bone metabolism. On the other hand, Tu et al (70) reported that femurs harvested from mice were transplanted into adiponectin knockout and wild-type mice. In the study, the growth of bone explants in adiponectin knock-out mice was significantly retarded, and micro-CT and histological analysis revealed reduced trabecular bone volume, decreased cortical bone, and increased osteoclast number in bone explants in adiponectin knock-out mice. Their findings propose the benefits of avoiding the long term adaptation and compensation mechanism, which might be seen in knockout and transgenic overexpression mice. In addition, Jiang et al (75) examined the effect of intermittent adiponectin administration on bone regeneration following distraction osteogenesis. In their experiments, rapid unilateral mandibular osteodistraction was performed on New Zealand white rabbits, and adiponectin or a vehicle was injected into the distraction gap. Under rapid distraction, immature bone formation was observed in the distracted callus from the control group, whereas DXA revealed greater bone formation and higher $\mathrm{BMD}$ and $\mathrm{BMC}$ of the distracted callus in the group with administration of adiponectin. Micro-CT, histological, and mechanical strength analyses also confirmed increased bone volume and greater strength of the mandible in the adiponectin treatment group compared with controls. These studies indicate that adiponectin might be a potential target for combating bone loss in bone metabolic disorders such as osteoporosis and also for healing bone fractures.

The effects of resistin and visfatin on osteoblasts and osteoclasts

Resistin is a $12.5 \mathrm{kD}$ or $10 \mathrm{kD}$ cysteine-rich polypeptide hormone and originally named for its ability to induce insulin resistance $(76,77)$. Resistin is expressed mainly from mature adipocytes in rodents, whereas in humans it is produced predominantly in inflammatory cells, especially in macrophages (78). It was found that resistin is expressed with the highest concentration in bone marrow. Previously, Thommesen et al (79) reported that resistin is expressed in osteoblastic and osteoclastic cells and involved in their differentiation. The mRNA of resistin was expressed in not only adipocytes but also MC3T3-E1, RAW 264.7, and primary human osteoblasts. The protein was also detectable in these cells by Western blot analysis. Recombinant resistin increased the number of differentiated osteoclasts and stimulated nuclear factor $\mathrm{k} B$ promoter activity. Also, resistin enhanced the proliferation of MC3T3-E1 cells in a PKA- and PKCdependent manner as well as the expression of interleukin- 6 in the cells, which is stimulator of osteoclast differentiation (80). These results suggest that resistin induces osteoclast activity directly and indirectly through stimulation of interleukin-6 (IL-6) expression in osteoblasts, leading to a reduction of bone mass.

Visfatin, also known as pre-B cell colony-enhancing factor (PBEF) and nicotinamide phosphoribosyltransferase (Nampt)], is a $52 \mathrm{kD}$ cytoplasmic protein abundantly produced by adipose tissue (81), and its expression in adipocytes and its concentration in plasma increase with obesity and type 2 diabetes (82). Visfatin binds to and activates the insulin receptor, thereby exerting insulin-mimetic effects as lowering blood glucose level (81). It has been shown that osteoblasts have a functional insulin receptor and that insulin stimulates collagen synthesis and differentiation of osteoblasts $(83,84)$. Indeed, deletion of insulin receptor in osteoblasts induced decreases in ALP activity and osteocalcin expression by suppressing a Runx 2 inhibitor, Twist 2 (85). Moreover, osteoblast-specific insulin receptor knockout mice displayed reduced bone accumulation due to decreased bone formation and deficient numbers of osteoblasts. It is thus assumed that visfatin carries signals from adipose tissue to bone and has an anabolic effect on bone mass. Visfatin phosphorylated insulin receptor, insulin substrate (IRS)-1, and IRS-2 in primary 


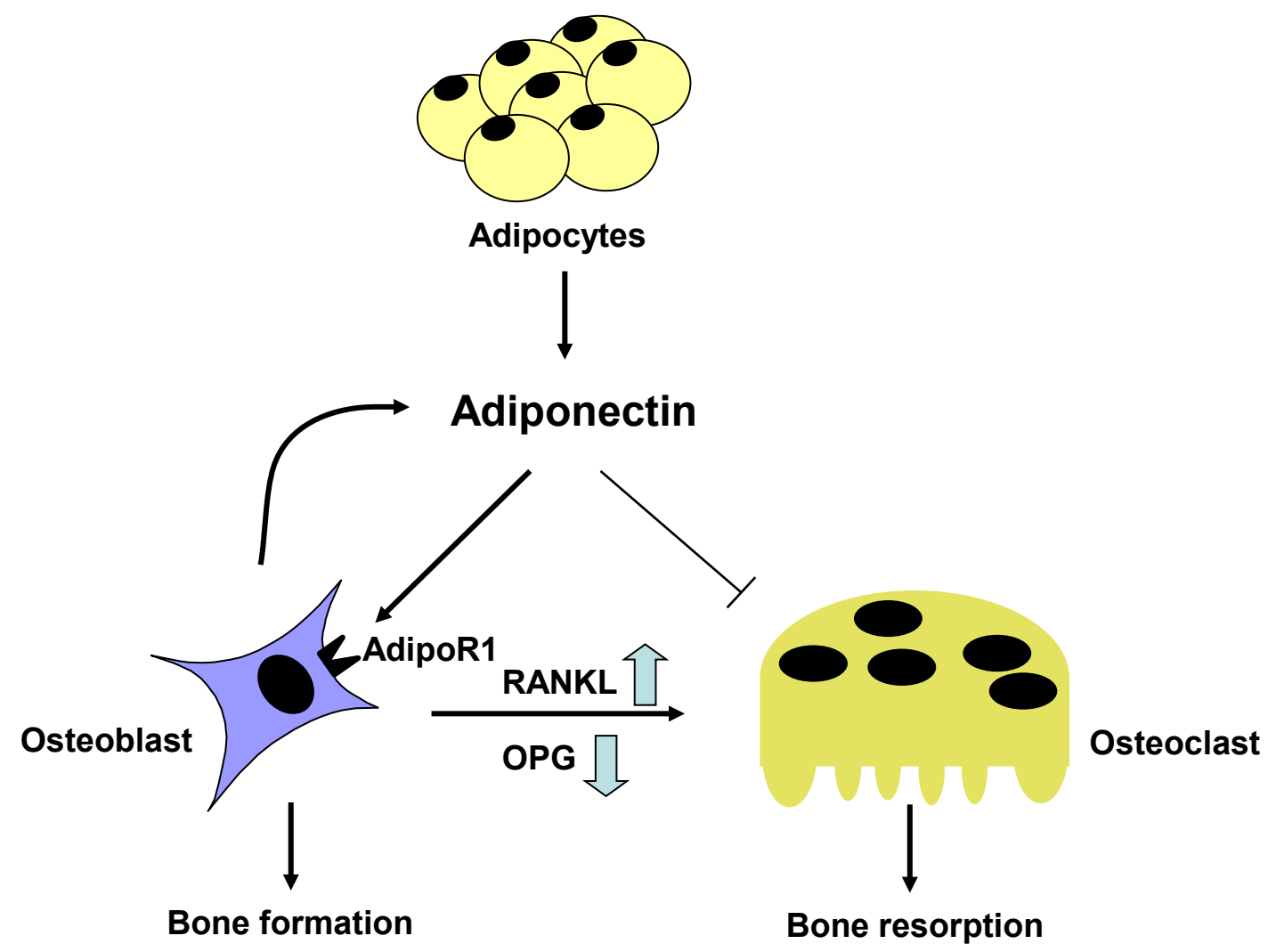

Figure 2. Schematic representation of the regulation of bone metabolism by adiponectin. Adiponectin and adiponectin receptor type 1 are expressed in osteoblasts. Adiponectin stimulates osteoblastogenesis and bone formation via the receptor. Adiponectin enhances the expression of RANKL and inhibits that of OPG, resulting in an activation of osteoclasts. On the other hand, adiponectin directly inhibits bone resorption. AdipoR1, adiponectin receptor type 1; RANKL, receptor activator for nuclear factor K B ligand; OPG, osteoprotegerin.

cultures of normal human osteoblast (86). Visfatin stimulated glucose uptake in the cells. It was observed that cell growth, ALP and type I collagen expression, as well as mineralization were enhanced by visfatin treatment. In addition, they showed that the effects of visfatin were similar to insulin and that the stimulatory effects of visfatin were completely abolished by a specific inhibitor of insulin receptor tyrosine kinase activity. However, it was found that both visfatin and insulin inhibited osteocalcin secretion from the human osteoblastic cells. Moschen et al (87) reported that visfatin also affects osteoclasts. Visfatin treatment significantly inhibited osteoclast formation induced by RANKL and M-CSF in a dose-dependent manner. Moreover, suppression of mRNA expression of RANK, NFATc1, and Cathepsin$\mathrm{K}$ by visfatin was observed in osteoclastic cells. Taken together, visfatin stimulates the proliferation and differentiation of osteoblasts through activation of insulin receptor and inhibits osteoclastogenesis, suggesting that visfatin has beneficial effects on bone mass.

\section{Endocrine loop between bone and adipose tissue}

In addition to its classical functions in biomechanical homeostasis, bone has recently been regarded as an endocrine organ. Osteocalcin, one of the osteoblast-specific secreted proteins, has several hormonal features and is secreted into the general circulation by osteoblastic cells. It has been shown that serum osteocalcin (uncarboxylated form) has a beneficial effect on glucose and fat metabolism $(88,89)$. Osteocalcin increases the expression of insulin in pancreatic b cells as well as that of adiponectin in adipocytes, resulting in preventing the development of metabolic diseases, obesity, and type 2 diabetes in wild-type mice (89). Recently, insulin receptor signaling in osteoblasts is shown to control osteoblast development and osteocalcin expression and regulate peripheral adiposity and glucose metabolism $(90,91)$, indicating the existence of a bone-pancreas endocrine loop through the function of insulin and osteocalcin. Since the previous studies described above have shown that adiponectin is involved in osteoblastogenesis and bone turnover and that os- 
teocalcin stimulates the expression of adiponectin in adipocytes, it is rational to hypothesize that an endocrine loop modulated by the activity of adiponectin and osteocalcin exists between bone and adipose tissue. On the other hand, leptin and resistin coordinate bone remodeling as described above. However, previous studies showed that osteocalcin did not affect the expression of leptin or resistin in adipose tissue $(87,92)$. Therefore, these two adipokines might not be involved in the function of osteocalcin on glucose metabolism.

\section{Conclusion}

Accumulating evidence indicates that adipokines are involved in bone metabolism. Leptin negatively regulates bone mass accumulation via the central nervous system, whereas leptin has direct positive effects on bone formation and remodeling. Systemic leptin administration induces a gain of bone mass, suggesting that leptin in the circulation may have a beneficial effect on bone growth and BMD. Adiponectin stimulates osteoblastogenesis and differentiation of osteoblasts through BMP-2 expression, and may affect osteoclast activity. Moreover, adiponectin enhances osteocalcin expression in osteoblasts, while osteocalcin alternatively stimulates adiponectin expression in adipocytes. Therefore, it is assumed that an endocrine loop may exist between bone and adipose tissue through adiponectin and osteocalcin. Furthermore, a few studies demonstrated that resistin and visfatin might affect bone metabolism. Further studies are necessary to understand the cross-talk between adipose tissue and bone.

\section{References}

1. Raisz LG. Pathogenesis of osteoporosis: Concepts, conflicts, and prospects. J Clin Invest 2005; 115: 3318-3325.

2. Center JR, Nguyen TV, Schneider D, Sambrook PN, Eisman JA. Mortality after all major types of osteoporotic fracture in men and women an observational study. Lancet 1999; 353: 878-882.

3. Cauley JA, Thompson DE, Ensrud KC, Scott JC, Black D. Risk of mortality following clinical fractures. Osteopos Int 2000; 11: 556-561.

4. Chrischilles EA, Butler CD, Davis CS, Wallace RB. A model of lifetime osteoporosis impact. Arch Intern Med 1991; 151: 2026-2032.

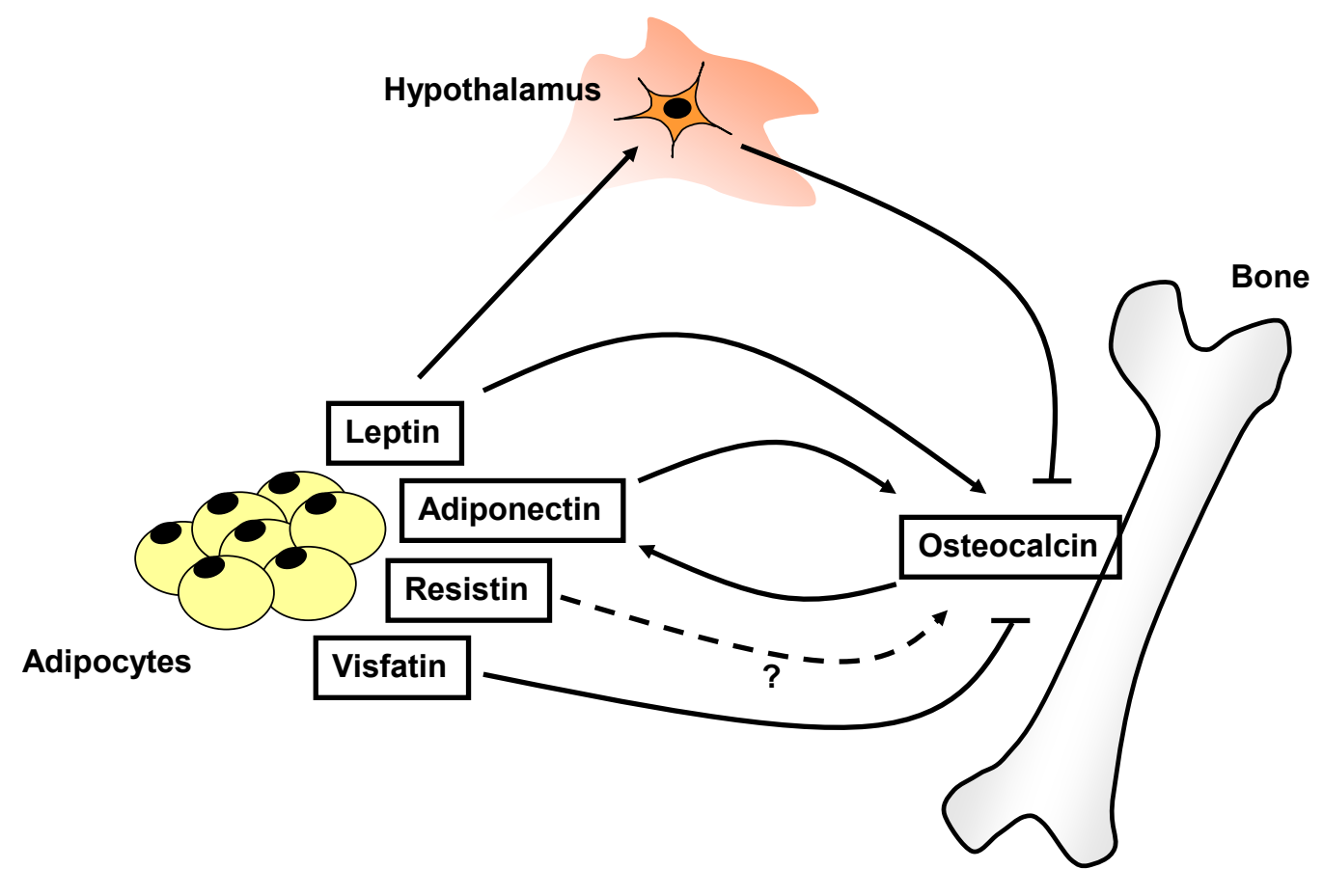

Figure 3. Endocrine loop between bone and adipose tissue (bone-adipose axis). Leptin directly stimulates osteocalcin expression in osteoblasts, whereas leptin inhibits osteocalcin activity via the central nervous system. Adiponectin enhances osteocalcin expression in osteoblasts, while osteocalcin in turn increases the expression of adiponectin in adipocytes. Although resistin receptor is reported to be expressed in osteoblasts, there is no report on the effect of resistin on osteocalcin expression to date. Visfatin stimulates osteoblast differentiation, it is, however, reported that visfatin inhibits osteocalcin expression. 
5. Harada S, Rodan GA. Control of osteoblast function and regulation of bone mass. Nature 2003; 423: 349-355.

6. Boyle WJ, Simonet WS, Lacey DL. Osteoclast differentiation and activation. Nature 2003; 423: 337-342.

7. Chaldakov GN, Stankulov IS, Hristova M, Ghenev PI. Adipobiology of disease: adipokines and adipokine-targeted pharmacology. Curr Pharm Des 2003; 9: 1023-1031.

8. Reid IR. Fat and bone. Arch Biochem Biophys 2010; 503: 2027.

9. Gymez-Ambrosi J, Rodriguez A, Catalan V, Frühbeck G. The bone-adipose axis in obesity and weight loss. Obes Surg 2008; 18: 1134-1143.

10. Gulcelik NE, Usman A, Gurlek A. Role of adipocytokines in predicting the development of diabetes and its late complications. Endocrine 2009; 36: 397-403.

11. Yamauchi M, Sugimoto T, Yamaguchi T, Nakaoka D, Kanazawa M, Yano S, et al. Plasma leptin concentrations are associated with bone mineral density and the presence of vertebral fractures in postmenopausal women. Clin Endocrinol 2001; 55: 341-347.

12. Kanazawa I, Yamaguchi T, Yamamoto M, Yamauchi M, Yano S, Sugimoto T. Relationships between serum adiponectin levels versus bone mineral density, bone metabolic markers, and vertebral fractures in type 2 diabetes mellitus. Eur J Endocrinol 2009; 160: 265-273.

13. Kanazawa I, Yamaguchi T, Yamauchi M, Yamamoto M, Kurioka S, Yano S, et al. Adiponectin is associated with changes in bone markers during glycemic control in type 2 diabetes mellitus. J Clin Endocrinol Metab 2009; 94: 3031-3037.

14. Belgardt BF, Bruning JC. CNS leptin and insulin action in the control of energy homeostasis. Ann N Y Acad Sci 2010; 1212: 97-113.

15. Hausman GJ, Barb CR. Adipose tissue and the reproductive axis: biological aspects. Endocr Dev 2010; 19: 31-44.

16. Weyer C, Funahashi T, Tanaka S, Hotta K, Matsuzawa Y, Pratley RE, et al. Hypoadiponectemia in obesity and type 2 diabetes: close association with insulin resistance and hyperinsulinemia. J Clin Endocrinol Metab 2001; 86: 19301935.

17. Scherer PE, Williams S, Fogliano M, Baldini G, Lodish HF. A novel serum protein similar to $\mathrm{C} 1 \mathrm{q}$, produced exclusively in adipocytes. J Biol Chem 1995; 270: 26746-26749.

18. Yamauchi T, Kamon J, Ito Y, Tsuchida A, Yokomizo T, Kita S, et al. Cloning of adiponectin receptors that mediate antidiabetic metabolic effects. Nature 2003; 423: 762-769.

19. Kadowaki T, Yamauchi T, Kubota N, Hara K, Ueki K, Tobe $\mathrm{K}$. Adiponectin and adiponectin receptors in insulin resistance, diabetes, and the metabolic syndrome. J Clin Invest
2006; 116: 1784-1792.

20. Kanazawa I, Yamaguchi T, Yano S, Yamauchi M, Yamamoto $\mathrm{M}$, Sugimoto T. Adiponectin and AMP kinase activator stimulate proliferation, differentiation, and mineralization of osteoblastic MC3T3-E1 cells. BMC Cell Biol 2007; 8: 51.

21. Berner HS, Lyngstadaas SP, Spahr A, Monjo M, Thommesen $\mathrm{L}$, Drevon CA, et al. Adiponectin and its receptors are expressed in bone-forming cells. Bone 2004; 35: 842-849.

22. Luo XH, Guo LJ, Yuan LQ, Xie H, Zhou HD, Wu XP, et al. Adiponectin stimulates human osteoblasts proliferation and differentiation via the MAPK signaling pathway. Exp Cell Res 2005; 309: 99-109.

23. Sridhar GR, Lakshmi G. Bone-derived secetory proteins and glucose and energy homeostasis. Adipobiology 2010, 2: 67-72.

24. Chaldakov GN, Fiore M. Human body as a multicrine gland. Adipobiology 2010, 2: 73-76.

25. Flier JS. What's in a name? In search of leptin's physiologic role. J Clin Endocrinol Metab 1998; 83: 1407-1413.

26. Zhang YY, Proenca R, Maffei M, Barone M, Leopold L, Friedman JM. Positional cloning of the mouse obese gene and its human homolog. Nature 1994; 372: 425-432.

27. Friedman JM, Leibel RL, Siegel DS, Walsh J, Bahary N. Molecular mapping of the mouse Ob mutation. Genomics 1991; 11: 1054-1062.

28. Tartaglia LA. The leptin receptor. J Biol Chem 1997; 272: 6093-6096.

29. Coleman DL, Hummel KP. Comparison of obesity syndromes of obese $(\mathrm{Ob} / \mathrm{Ob})$ and diabetic $(\mathrm{Db} / \mathrm{Db})$ mice. Diabetologia 1972; 8: 49.

30. Lorentzon R, Alehagen U, Boquist L. Osteopenia in mice with genetic diabetes. Diabetes Res Clin Pract 1986; 2: 157163.

31. Steppan CM, Crawford DT, Chidsey-Frink KL, Ke H, Swick AG. Leptin is a potent stimulator of bone growth in ob/ob mice. Regul Pept 2000; 92: 73-78.

32. Hamrick MW, Della-Fera MA, Choi YH, Pennington C, Hartzell D, Baile CA. Leptin treatment induces loss of bone marrow adipocytes and increases bone formation in leptindeficient ob/ob mice. J Bone Miner Res 2005; 20: 994-1001.

33. Williams GA, Callon KE, Watson M, Costa JL, Ding Y, Dickinson $\mathrm{M}$, et al. Skeletal phenotype of the leptin receptor-deficient $d b / d b$ mouse. J Bone Miner Res 2011; 26: 1698-1709.

34. Ducy P, Amling M, Takeda S, Priemel M, Schilling AF, Beil FT, et al. Leptin inhibits bone formation through a hypothalamic relay: a central control of bone mass. Cell 2000; 100: 197-207.

35. Baldock PA, Sainsbury A, Couzens M, Enriquez RF, Thomas 
GP, Gardiner EM, et al. Hypothalamic Y2 receptors regulate bone formation. J Clin Invest 2002; 109: 915-921.

36. Takeda S, Elefterious F, Levasseur R, Liu X, Zhao L, Parker $\mathrm{KL}$, et al. Leptin regulates bone formation via the sympathetic nervous system. Cell 2002; 111: 305-317.

37. Karsenty G.. Convergence between bone and energy homeostases: Review leptin regulation of bone mass. Cell Metab 2006; 4: 341-348.

38. Iwaniec UT, Boghossian S, Lapke PD, Turner RT, Kalra SP. Central leptin gene therapy corrects skeletal abnormalities in leptin-deficient ob/ob mice. Peptides 2007; 28: 1012-1019.

39. Kalra SP, Dube MG, Iwaniec UT. Leptin increases osteoblast-specific osteocalcin release through a hypothalamic relay. Peptides 2009; 30: 967-973.

40. Bartell SM, Rayalam S, Ambati S, Gaddam DR, Hartzell DL, Hamrick M, et al. Central (ICV) leptin injection increases bone formation, bone mineral density, muscle mass, serum IGF-I, and the expression of osteogenic genes in leptin-deficient ob/ob mice. J Bone Miner Res 2011; 26: 1710-1720.

41. Wauman J, Tavernier J. Leptin receptor signaling: pathways to leptin resistance. Front Biosci 2011; 17: 2771-2793

42. Driessler F, Baldock PA. Hypothalamic regulation of bone. $J$ Mol Endocrinol 2010; 45: 175-181.

43. Confavreux CB, Levine RL, Karsenty G. A paradigm of integrative physiology, the crosstalk between bone and energy metabolisms. Mol Cell Endocrinol 2009; 310: 21-29.

44. Lee YJ, Park JH, Ju SK, You KH, Ko JS, Kim HM. Leptin receptor isoform expression in rat osteoblasts and their functional analysis. FEBS Lett 2002; 528: 43-47.

45. Scheller EL, Song J, Dishowitz MI, Soki FN, Hankenson KD, Krebsbach PH. Leptin functions peripherally to regulate differentiation of mesenchymal progenitor cells. Stem Cells 2010; 28: 1071-1080.

46. Takahashi Y, Okimura Y, Mizuno I, Iida K, Takahashi T, Kaji $\mathrm{H}$, et al. Leptin induces mitogen-activated protein kinasedependent proliferation of C3H10T1/2 cells. J Biol Chem 1997; 272: 12897-12900.

47. Burguera B, Brunetto A, Garcia-Ocana A, Teijeiro R, Esplen $\mathrm{J}$, Thomas $\mathrm{T}$, et al. Leptin increases proliferation of human steosarcoma cells through activation of PI(3)-K and MAPK pathways. Med Sci Monit 2006; 12: BR341-349.

48. Cornish J, Callon KE, Bava U, Lin C, Naot D, Hill BL, et al. Leptin directly regulates bone cell function in vitro and reduces bone fragility in vivo. J Endocrinol 2002; 175: 405-415.

49. Thomas T, Gori F, Khosla S, Jensen MD, Burguera B, Riggs BL. Leptin acts on human marrow stromal cells to enhance differentiation to osteoblasts and to inhibit differentiation to adipocytes. Endocrinology 1999; 140: 1630-1638.
50. Peng M, Chen S, Fang W, Yu X. Effects of leptin on the expression of a1 (I) collagen gene in human osteoblast-like MG63 cells. Biochem Cell Biol 2010; 88: 683-686.

51. Chang YJ, Shih DT, Tseng CP, Hsieh TB, Lee DC, Hwang SM. Disparate mesenchymal-lineage tendencies in mesenchymal stem cells from human bone marrow and umbilical cord blood. Stem Cells 2006; 24: 679-685.

52. Reseland JE, Syversen U, Bakke I, Qvigstad G, Eide LG, Hjertner $\mathrm{O}$, et al. Leptin is expressed in and secreted from primary cultures of human osteoblasts and promotes bone mineralization. J Bone Miner Res 2001; 16: 1426-1433.

53. Gordeladze JO, Drevon CA, Swersen U, Reseland JE. Leptin stimulates human osteoblastic cell proliferation, de novo collagen synthesis, and mineralization: Impact on differentiation markers, apoptosis, and osteoclastic signaling. J Cell Biochem 2002; 85: 825-836.

54. Martin A, de Vittoris R, David V, Moraes R, Begeot M, Lafage-Proust $\mathrm{MH}$, et al. Leptin modulates both resorption and formation while preventing disuse-induced bone loss in tail-suspended female rats. Endocrinology 2005; 146: 36523659.

55. Burguera B, Hofbauer LC, Thomas T, Gori F, Evans GL, Khosla S, et al. Leptin reduces ovariectomy-induced bone loss in rats. Endocrinology 2001; 142: 3546-3553.

56. Jackson MA, Iwaniec UT, Turner RT, Wronski TJ, Kalra SP. Effects of increased hypothalamic leptin gene expression on ovariectomy-induced bone loss in rats. Peptides 2011; 32: 1575-1580.

57. Berner HS, Lyngstadaas SP, Spahr A, Monjo M, Thommesen $\mathrm{L}$, Drevon CA, et al. Adiponectin and its receptors are expressed in bone-forming cells. Bone 2004; 35: 842-849.

58. Yokota T, Meka CS, Kouro T, Medina KL, Igarashi H, Takahashi $\mathrm{M}$, et al. Adiponectin, a fat cell product, influences the earliest lymphocyte precursors in bone marrow cultures by activation of the cyclooxygenase-prostaglandin pathway in stromal cells. J Immunol 2003; 171: 5091-5099.

59. Luo XH, Guo LJ, Yuan LQ, Xie H, Zhou HD, Wu XP, et al. Adiponectin stimulates human osteoblasts proliferation and differentiation via the MAPK signaling pathway. Exp Cell Res 2005; 309: 99-109.

60. Williams GA, Wang Y, Callon KE, Watson M, Lin JM, Lam $\mathrm{JB}$, et al. In vitro and in vivo effects of adiponectin on bone. Endocrinology 2009; 150: 3603-3610.

61. Yamauchi T, Kadowaki T. Physiological and pathophysiological roles of adiponectin and adiponectin receptors in the integrated regulation of metabolic and cardiovascular diseases. Int J Obes 2008; 7: S13-18.

62. Kanazawa I, Yamaguchi T, Yano S, Yamauchi M, Sugimoto 
T. Activation of AMP-kinase and inhibition of Rho-kinase induce the mineralization of osteoblastic MC3T3-E1 cells through endothelial NOS and BMP-2 expression. Am J Physiol Endocrinol Metab 2009; 296: E139-146.

63. Huang CY, Lee CY, Chen MY, Tsai HC, Hsu HC, Tang CH. Adiponectin increases BMP-2 expression in osteoblasts via AdipoR receptor signaling pathway. J Cell Physiol 2010; 224: 475-483.

64. Lee HW, Kim SY, Kim AY, Lee EJ, Choi JY, Kim JB. Adiponectin stimulates osteoblast differentiation through induction of COX2 in mesenchymal progenitor cells. Stem Cells 2009; 27: 2254-2262.

65. Tu Q, Zhang J, Dong LQ, Saunders E, Luo E, Tang J, et al. Adiponectin inhibits osteoclastogenesis and bone resorption via APPL1-mediated suppression of Akt1. J Biol Chem 2011; 286: 12542-12553.

66. Shinoda Y, Yamaguchi M, Ogata N, Akune T, Kubota N, Yamauchi $\mathrm{T}$, et al. Regulation of bone formation by adiponectin through autocrine/paracrine and endocrine pathways. J Cell Biochem 2006; 99: 196-208.

67. Oshima K, Nampei A, Matsuda M, Iwaki M, Fukuhara A, Hashimoto J, et al. Adiponectin increases bone mass by suppressing osteoclast and activating osteoblast. Biochem Biophys Res Commun 2005; 331: 520-526.

68. Yamaguchi N, Kukita T, Li YJ, Martinez Argueta JG, Saito T, Hanazawa S, et al. Adiponectin inhibits osteoclast formation stimulated by lipopolysaccharide from actinobacillus actinomycetemcomitans. FEMS Immunol Med Microbiol 2007; 49: 28-34.

69. Yamaguchi N, Kukita T, Li YJ, Kamio N, Fukumoto S, Nonaka K, et al. Adiponectin inhibits induction of TNF-alpha/ RANKL-stimulated NFATc1 via the AMPK signaling. FEBS Lett 2008; 582: 451-456.

70. Williams GA, Wang Y, Callon KE, Watson M, Lin JM, Lam $\mathrm{JB}$, et al. In vitro and in vivo effects of adiponectin on bone. Endocrinology 2009; 150: 3603-3610.

71. Luo XH, Guo LJ, Xie H, Yuan LQ, Wu XP, Zhou HD, et al. Adiponectin stimulates RANKL and inhibits OPG expression in human osteoblasts through the MAPK signaling pathway. J Bone Miner Res 2006; 21: 1648-1656.

72. Mitsui Y, Gotoh M, Fukushiman N, Shirachi I, Otabe S, Yuan X, et al. Hyperadiponectinema enhances bone formation in mice. BMC Musculoskelet Disord 2011; 12: 18.

73. Ealey KN, Kaludjerovic J, Archer MC, Ward WE. Adiponectin is a negative regulator of bone mineral and bone strength in growing mice. Exp Biol Med 2008; 233: 1546-1553.

74. Kubota N, Terauchi Y, Yamauchi T, Kubota T, Moroi M, Matsui J, et al. Disruption of adiponectin causes insulin re- sistance and neointimal formation. J Biol Chem 2002; 277 : 25863-25866.

75. Jiang X, Song D, Ye B, Wang X, Song G, Shoukang Y, et al. Effect of intermittent administration of adiponectin on bone regeneration following mandibular osteodistraction in rabbits. J Orthop Res 2011; 29: 1081-1085.

76. Steppan CM, Bailey ST, Bhat S, Brown EJ, Banerjee RR, Wright CM, et al. The hormone resistin links obesity to diabetes. Nature 2011; 409: 307-312.

77. Rajala MW, Lin Y, Ranalletta M, Yang XM, Qjan H, Gingerich R, et al. Cell type-specific expression and coregulation of murine resistin and resistin-like molecule-alpha in adipose tissue. Mol Endocrinol 2002; 16: 1920-1930.

78. Patel L, Buckels AC, Kinghorn IJ, Murdock PR, Holbrook JD, Plumpton C, et al. Resistin is expressed in human macrophages and directly regulated by PPAR gamma activators. Biochem Biophys Res Commun 2003; 300: 472-476.

79. Thommesen L, Stunes AK, Monjo M, Grosvik K, Tamburstuen MV, Kjobli E, et al. Expression and regulation of resistin in osteoblasts and osteoclasts indicate a role in bone metabolism. J Cell Biochem 2006; 99: 824-834.

80. Ishimi Y, Miyaura C, Jin CH, Akatsu T, Abe E, Nakamura Y, et al. IL-6 is produced by osteoblasts and induces bone resorption. J Immunol 1990; 145: 3297-3303.

81. Fukuhara A, Matsuda M, Nishizawa M, Segawa K, Tanaka $\mathrm{M}$, Kishimoto K, et al. Visfatin: a protein secreted by visceral fat that mimics the effects of insulin. Science 2005; 307: 426430.

82. Berndt J, Kloting N, Kralisch S, Kovacs P, Fasshauer M, Schon MR, et al. Plasma visfatin concentrations and fat depot-specific mRNA expression in humans. Diabetes 2005; 54: 2911-2916.

83. Pun KK, Lau P, Ho PW. The characterization, regulation, and function of insulin receptors on osteoblast-like clonal osteosarcoma cell line. J Bone Miner Res 1989; 4: 853-862.

84. Kream BE, Smith MD, Canalis E, Raisz LG. Characterization of the effect of insulin on collagen synthesis in fetal rat bone. Endocrinology 1985; 116: 296-302.

85. Fulzele K, Riddle RC, Digirolamo DJ, Cao X, Wan C, Chen $\mathrm{D}$, et al. Insulin receptor signaling in osteoblasts regulates postnatal bone acquisition and body composition. Cell 2010; 142: 309-319.

86. Xie H, Tang SY, Luo XH, Huang J, Cui RR, Yuan LQ, et al. Insulin-like effects of visfatin on human osteoblasts. Calcif Tissue Int 2007; 80: 201-210.

87. Moschen AR, Geiger S, Gerner R, Tilg H. Pre-B cell colony enhancinf factor/NAMPT/visfatin and its role in inflammation-related bone disease. Mutat Res 2010; 690: 95-101. 
88. Lee NK, Sowa H, Hinoi E, Ferron M, Ahn JD, Confavreux $\mathrm{C}$, et al. Endocrine regulation of energy metabolism by the skeleton. Cell 2007; 130: 456-469.

89. Ferron M, Hinoi E, Karsenty G, Ducy P. Osteocalcin differentially regulates beta cell and adipocyte gene expression and affects the development of metabolic diseases in wildtype mice. Proc Natl Acad Sci USA 2008; 105: 5266-5270.

90. Fulzele K, Riddle RC, Digirolamo DJ, Cao X, Wan C, Chen $\mathrm{D}$, et al. Insulin receptor signaling in osteoblasts regulates postnatal bone acquisition and body composition. Cell 2010; 142: 309-319.

91. Ferron M, Wei J, Yoshizawa T, Del Fattore A, DePinho RA, Teti A, et al. Insulin signaling in osteoblasts integrates bone remodeling and energy metabolism. Cell 2010; 142: 296-308.

92. Rached MT, Kode A, Silva BC, Jung DY, Gray S, Ong H, et al. FoxO1 expression in osteoblasts regulates glucose homeostasis through regulation of osteocalcin in mice. J Clin Invest 2010; 120: 357-368. 